\title{
E्己̌reAáo \\ Viver Através de Projetos de Saúde: práticas de educação em saúde no Brasil
}

\author{
Lucas Pereira de Melo' \\ Ana Luiza de Oliveira e Oliveira'
}

'Universidade Federal do Rio Grande do Norte (UFRN), Caicó/RN - Brasil

RESUMO - Viver Através de Projetos de Saúde: práticas de educação em saúde no Brasil. O objetivo deste ensaio é analisar os saberes e as práticas de educação em saúde no Brasil tomando como objeto sua emergência histórica na segunda década do século XX, como educação sanitária, e seus desdobramentos mais recentes. Tais saberes e práticas são analisados por meio dos conceitos de práticas discursivas e biopolítica de Michel Foucault. A discussão se inicia com a emergência da educação sanitária no Brasil nos anos 1920 e de suas práticas até a década de 1960, quando ocorre a mudança terminológica para educação em saúde. Por fim, abordam-se alguns dos desdobramentos hodiernos das práticas de educação em saúde e seus traços biopolíticos no contexto marcado pelas estratégias de reorientação do modelo de atenção à saúde no país.

Palavras-chave: Educação em Saúde. Práticas de Saúde Pública. Biopolítica.

ABSTRACT - Living through Health Projects: health education's practices in Brazil. This paper aims to analyse the health education's practices in Brazil taking as object its historical emergence as sanitary education in the 1920s, and its latest developments. The Michel Foucault's concepts of discursive practices, and biopolitic guided this analysis. The discussion began with the emergence of sanitary education in Brazil in the 1920s and their practices until the 1960s when there is a terminological shift to health education. Finally, were approached some contemporary developments of health education practices and their biopolitical traces in a context marked by strategies for reorienting the health care model in the country.

Keywords: Health Education. Public Health Practices. Biopolitic.

Educação \& Realidade, Porto Alegre, v. 42, n. 3, p. 961-980, jul./set. 2017. 961 http://dx.doi.org/10.1590/2175-623656335 
Viver Através de Projetos de Saúde

\section{Introdução}

A educação em saúde é um campo de saberes, agentes e práticas que historicamente esteve vinculado às ações de saúde pública. Tal vinculação busca lograr objetivos diversos que variam ao longo do tempo de acordo com a conjuntura política do setor. Dessa forma, da transformação de hábitos por meio de orientações de higiene à promoção da autonomia e do autocuidado do indivíduo, essas práticas educativas seguem construindo seu percurso transversal no interior das práticas sanitárias em geral.

Diante disso, temos trabalhado com o pressuposto da existência de um conjunto de práticas discursivas que, historicamente, tem sustentado as ações de educação em saúde e, em dados contextos, impedido ou dificultado a produção de cuidados congruentes com as necessidades do usuário (Melo, 2013). Para Foucault (2010a), as práticas discursivas são os lugares onde se formam ou se deformam, onde aparecem e apagam-se séries emaranhadas de objetos - como jogos de diferenças, de desvios, de substituições, de transformações, ao mesmo tempo superpostas e lacunares. Esses objetos não são produzidos no interior desses discursos, mas em determinadas condições de externalidade que lhes permitem aparecer, justapor-se a outros objetos, situar-se em relação a eles, definir sua diferença, sua irredutibilidade e, eventualmente, sua heterogeneidade, permitem, enfim, que sejam colocados em um campo de externalidade.

Portanto, as práticas discursivas não se produzem e se encerram em si mesmas. Igualmente não há o papel positivo do autor, da disciplina, da vontade de saber. O que há, é um recorte e uma rarefação do discurso (Foucault, 2010b). Essas práticas se inserem, em todo caso, em um contexto de relações que reclama as instâncias de emergência, de delimitação e de especificação desses discursos. Nessa perspectiva, as práticas de educação em saúde não têm o objetivo único e altruísta da promoção da saúde, da salvação ou do prolongamento da vida. Trata-se de um discurso que recai sobre o sujeito e suas formas de andar a vida. Assim, produzem-se tecnologias reguladoras, normas e padrões para a população e sua multiplicidade de processos vitais. Nesse sentido, segundo Gastaldo (1997), a educação em saúde se mostra como uma experiência de ser governado por outros e uma solicitação de autogoverno e autodisciplina, ou seja, é uma estratégia biopolítica.

Nessa perspectiva, o termo biopolítica designa o que faz a vida e seus mecanismos entrarem no domínio dos cálculos explícitos e faz do poder-saber (nesse caso, o biopoder) um agente de transformação da vida humana. Trata-se da assunção da vida pelo poder - uma tomada de poder sobre o homem enquanto ser vivo, uma espécie de estatização do biológico (Foucault, 2002; 2010c).

Dito isso, fica delineado um lugar sempre atravessado, permeado por influências, afinal: como? De onde? O quê? Quando? Com quem? Contra quem nós falamos? É na materialidade de nossas relações cotidianas, de nossos encontros e desencontros, das descobertas, recepções 
e decepções que o lugarvai tomando contornos. É sempre bom lembrar que tais contornos não se pretendem fixos. Na verdade, são contornos em jogos de apagamentos, de riscos e de rabiscos. Além disso, esses contornos não são o lugar, eles apenas circunscrevem um vazio, um não lugar; assim como um jarro não é apenas o barro que o constitui, mas também o vazio delimitado pelo barro.

O lugar de onde estamos e estaremos falando ancora-se nos escritos de Michel Foucault. Trata-se de uma tentativa de habitar esses espaços e aí poder dialogar com o próprio pensamento do autor e com os "leitores já velhos de Foucault", como disse Larrosa (2004). Mas, usando a mesma estrutura sintática de Larrosa (2004), esse diálogo já é, talvez para sempre, um problema, e o dialogar (n)deste lugar já se tornou, para nós, e talvez para sempre, o mais difícil.

$\mathrm{O}$ arquivo que estará sendo operado neste artigo é constituído pelos saberes e pelas práticas de educação em saúde tomadas, inicialmente, numa perspectiva histórica. A partir disso, realizou-se um ensaio de seus desdobramentos mais recentes. Esse arquivo relaciona-se diretamente com o tempo no qual estamos situados: o presente, o contemporâneo, visto que toda prática é uma prática em situação.

Tendo como base a discussão sobre "ensaiar no presente", realizada por Larrosa (2004), nesta investigação o tempo presente é tomado como uma experiência. Nesse sentido, pensar o presente dos saberes e das práticas de Educação em Saúde tem a potência de problematizar: "o que nos acontece agora, quem somos agora, o que podemos pensar e o que podemos dizer e o que podemos experimentar agora, neste exato momento da história" (Larrosa, 2004, p. 34). Com isso, o que buscamos analisar não é o passado como uma narrativa cronológica, heroica e factual. Pelo contrário, estamos preocupados em evidenciar como esse passado construiu social, política e historicamente o que somos hoje. Trata-se, portanto, de desfamiliarizar, desnaturalizar, produzir rupturas no presente a partir da máscara do passado. Por isso, ensaiar no presente requer a produção de uma certa distância que nos permita estar dentro e fora do tempo e, assim, assumir uma atitude crítica diante da vida e da experiência. Para Agamben (2009), essa operação consiste numa arqueologia que não toma como objeto de análise um passado remoto, mas tudo aquilo que no presente não podemos viver.

Dessa forma, o objetivo deste ensaio é analisar os saberes e as práticas de educação em saúde no Brasil tomando como objeto sua emergência histórica nos anos 1920, como educação sanitária, e seus desdobramentos mais recentes.

\section{Metodologia}

Este texto foi produzido no contexto de uma pesquisa maior, que teve como produto final uma tese de Doutorado. Trata-se de ensaio no qual os autores se propõem a realizar uma reflexão teórica com base em estudo bibliográfico (Gil, 1999) e documental (Prior, 2011). 
Viver Através de Projetos de Saúde

Nesse contexto, partimos da elaboração de um plano de trabalho, cujo objetivo era analisar da educação sanitária à educação em saúde no Brasil e os desdobramentos recentes desse processo histórico. Em seguida, foram identificadas e obtidas as fontes capazes de fornecer as respostas adequadas à solução do problema proposto através de buscas em bases de dados, sites oficiais, documentos e bibliotecas. Na seleção documental consideramos a perspectiva de Prior (2011), que afirma ser necessário afastar-se do documento como artefato estático e entendê-lo como material que integra campos de ação e que, portanto, só pode ser analisado quando contextualizado.

De posse da bibliografia, realizamos, primeiramente, uma leitura exploratória de todo o material para definir os textos a serem pesquisados; em seguida fizemos uma leitura seletiva, ou seja, uma leitura mais aprofundada das partes que realmente interessavam. O procedimento seguinte foi a leitura analítica, identificando as ideias-chave dos textos, ordenando-as e, finalmente, sintetizando-as. Por fim, procedemos a leitura interpretativa, estabelecendo relações entre o conteúdo das fontes pesquisadas e o referencial teórico, o que significou conferir um alcance mais amplo aos resultados obtidos com a leitura analítica.

Os elementos importantes obtidos a partir do material foram transcritos em fichas de documentação. Após o adequado fichamento, realizamos a construção lógica do trabalho que, segundo Gil (1999), consiste na organização das ideias a fim de atender os objetivos do trabalho para que ele possa ser entendido como uma unidade dotada de sentido. Por último, foi redigido o ensaio, que consiste na expressão literária do raciocínio desenvolvido no trabalho.

O presente ensaio está estruturado em três tópicos que emergiram como resultados da análise realizada: (1) A Emergência da Educação Sanitária no Brasil; (2) Da Educação Sanitária à Educação em Saúde; e (3) Desdobramentos Recentes das Práticas de Educação em Saúde no Brasil.

\section{A Emergência da Educação Sanitária no Brasil}

Educação e saúde, dois campos com desenvolvimento distintos, mas que se encontraram em dadas circunstâncias históricas. Diante de tal assertiva, fazem-se necessários alguns questionamentos: que situações de emergência reclamaram tal encontro? Por que esses campos, inicialmente paralelos, se encontraram em algum momento da história? O que houve (ou há) de fecundo nesse enlace, de maneira que sua separação se tornou impensável no presente? O que justifica o sentido de complementaridade que os envolve? Quais os efeitos produzidos por tal relacionamento? Há outras formas de produzir tais efeitos? Por que realizamos ações de educação em saúde? Por que fazemos dessa forma e não de outra?

Questionamentos pretensiosos esses! Sem assumir aqui o compromisso de responder a todos eles ou respondê-los agora, esboçaremos 
neste tópico uma perspectiva para descrever a emergência da educação sanitária no Brasil nos anos 1920.

A emergência da educação sanitária no Brasil ocorreu paralelamente ao desenvolvimento político-social da Saúde Pública. No período anterior a 1923, inexistia uma relação institucionalizada entre educação e saúde. Nesse período, vivia-se a fase do saneamento do meio, do controle das moléstias transmissíveis e da polícia sanitária. Melo (1976) enumerou alguns aspectos que marcaram a década de 1920 no país: o crescimento do setor industrial; o grande contingente de imigrantes e as novas ideias trazidas da Europa exigindo novas formas de relacionamento empregador-empregado; o crescimento da classe dos trabalhadores urbanos; a participação da classe média na arena política; o entusiasmo pela escolarização e o marcante otimismo pedagógico; e o perfil epidemiológico caracterizado por doenças transmissíveis, como o impaludismo e as verminoses.

Além desses aspectos relacionados ao contexto político, social e econômico, destacam-se aqueles que diziam respeito ao desenvolvimento científico-tecnológico, sobretudo pela constituição de ciências como a Psicologia, a Sociologia e a aplicação de suas teorias e métodos no campo da Pedagogia (Melo 1976).

Nesse cenário, destacamos a atuação de Geraldo Horácio de Paula Souza (1889-1951). Paula Souza recebeu as influências intelectuais do seu pai (Antonio Francisco de Paula Souza, fundador da Escola Politécnica de São Paulo) e do contexto dos últimos 50 anos do século XIX. Tendo se formado em Farmácia em 1908 pela Escola de Farmácia de São Paulo, ingressou, anos depois, na Faculdade de Medicina do Rio de Janeiro, onde se graduou em 1915. Durante seu curso de Medicina realizou estágios em laboratórios de química e em institutos médicos de Berlim, Zurique, Genebra e Paris. No período de 1918 a 1920 realizou seu doutorado em Higiene e Saúde Pública na School of Public Health da John Hopkins University, em Baltimore, Estados Unidos (Candeias, 1988; De Queiróz Pérez-Ramos, 2006).

De volta ao Brasil em 1922, Paula Souza assumiu o cargo de Diretor do Instituto de Higiene da Faculdade de Medicina de São Paulo e, na mesma época, se tornou responsável pela Direção Geral do Serviço de Saúde Pública do Estado de São Paulo. Como diretor desse órgão, propôs, em 1925, a reestruturação global dessa repartição estadual (Candeias, 1988).

Começa assim a ser delineada a trama de relações que possibilitaram a emergência do encontro entre os campos da educação e da saúde no Brasil, tendo como foco a população das grandes cidades e, posteriormente, das zonas rurais.

Foi com a reforma do Código Sanitário proposta por Paula Souza, decorrente do Decreto $n^{\circ} 3.876$, de 11 de julho de 1925, aprovado e submetido à modificação pela Lei no 2.121 , de 30 de dezembro do mesmo ano, que teve origem uma auxiliar, de nível médio, explicitada nas referidas formulações: a educadora sanitária. Entre outras inovações, pro- 
pôs a criação da Inspetoria de Educação Sanitária, de Centros de Saúde e a inclusão do Curso de Educação Sanitária no Instituto de Higiene ${ }^{1}$ da Faculdade de Medicina de São Paulo (Candeias, 1988).

A proposta de criação do Curso de Educação Sanitária por Paula Souza fundamentava-se em suas experiências norte-americanas e no fato de haver um reconhecimento, a nível internacional, da importância dessa prática de saúde pública e, no caso específico de São Paulo, a inexistência de enfermeiras na rede de serviços do Estado (Candeias, 1988). Aponta-se ainda o fato de que a Escola de Enfermagem da Universidade de São Paulo (USP) foi criada pelo Decreto-Lei no 13.040, em 31 de dezembro de 1942, portanto, dezessete anos depois da criação do curso de Educação Sanitária.

De acordo com o Decreto no 3.876 (Brasil, 1925), cabia à Inspetoria de Educação Sanitária "promover a formação da consciência sanitária da população em geral”. Para Paula Souza, a educação sanitária deveria se desenvolver com toda a generalidade possível e pelos processos mais práticos, de modo a impressionar e convencer os educandos a implantar hábitos de higiene. As práticas da educação sanitária se dirigiam ao indivíduo isoladamente ou a grupos, se conviesse, sendo desenvolvida nos Centros de Saúde, em visitas domiciliares, em estabelecimentos escolares $^{2}$, hospitalares e fabris, entre outros (Candeias, 1988).

Nesse panorama, cumpre assinalar o papel da escola e do centro de saúde, este último recém-criado, como espaços privilegiados na produção de saberes e de práticas de educação sanitária. Marques (1994) aponta que no projeto eugenista que se desenvolveu, principalmente no Estado de São Paulo, a escola assumiu o papel de uma instituição social modeladora, onde os discursos higienista e eugênico aperfeiçoavam o corpo e o espírito da criança (Figura 1). Nesse espaço institucional, mais tarde também cenário de prática das educadoras sanitárias, os corpos eram inseridos numa ordem disciplinar que através de diversos mecanismos deveria produzir a criança higienizada, dócil, apta, civilizada, sã e viril - o retrato do povo brasileiro rabiscado pelos eugenistas. Essa educação que edificava o corpo - um corpo com cor, classe, gênero, sexualidade - contou com a vigilância constante de médicos, educadoras sanitárias e professores, como num panóptico (Figura 2). Vigilância essa que deveria se estender ao universo familiar, doméstico (Vasconcellos; Rodrigues, 2006) e que caberá, também, a outro equipamento: o centro de saúde. 
Figura 1 - Crianças Enfileiradas no Pátio da Escola para Escovação dos Dentes

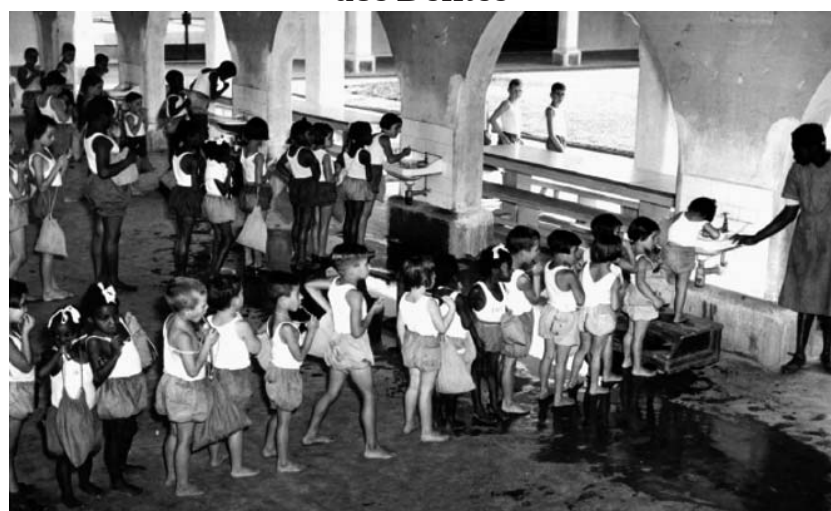

Fonte: Vasconcellos e Rodrigues (2006).

Figura 2 - Educadora Sanitária Fiscalizando o Acondicionamento e a Preparação dos Alimentos na Escola

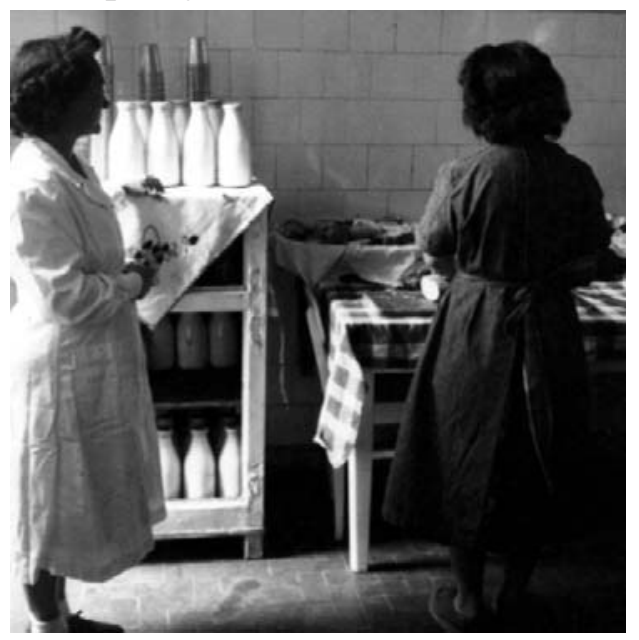

Fonte: Vasconcellos e Rodrigues (2006).

O centro de saúde emerge nesse contexto como um serviço de saúde pública responsável pela execução das práticas de educação sanitária ou higiênica, dentre outras funções. Cortez (1926) afirma, em sua Tese de Doutorado, que caberá a esses serviços produzir a consciência sanitária no povo - condição sine qua non para transformar o meio ambiente e os hábitos de higiene. Para tanto, caberia aos profissionais dos centros de saúde realizar ações de educação por meio dos princípios da higiene como forma de elevar o nível moral e físico da nossa raça e a formação de uma gente viril e sã.

Como se observa, os preceitos da Higiene configuravam-se como um elemento fundamental a serviço da Ciência Sanitária e Eugênica. Tais preceitos ficaram evidentes na aula inaugural proferida por Nico- 
Viver Através de Projetos de Saúde

lino Moreno em janeiro de 1946 no Curso de Saúde Escolar, promovido pelo Serviço Médico-Escolar do Departamento de Educação do Estado de São Paulo. Para o autor, a higiene preserva e aprimora a saúde e, somente por meio dela, seria possível produzir, para o povo pobre, projetos de vida regrada, uma maneira sadia de se viver. Essa ciência da vida, nos dizeres de Moreno (1946), estabelecia as normas necessárias para o perfeito desenvolvimento físico, intelectual e moral, aplicáveis a todos os instantes da vida. Tratava-se, assim, de uma tecnologia para o aperfeiçoamento do indivíduo, circunscrita a ele e a seu meio ambiente imediato, por meio da qual cada um deveria se fazer cada vez mais útil à coletividade.

A missão que se ia estabelecendo no interior deste discurso era a necessidade de inculcar na população os preceitos e os dogmas da Higiene num projeto nitidamente eugenista. Nesse sentido, a escola emerge como o cenário ideal, sobretudo pelo preparo das educadoras sanitárias que eram, em sua maioria, professoras primárias. Já para o trabalho fora do contexto escolar inexistia uma metodologia própria para o trabalho educativo. Devido a essa deficiência, a educação sanitária assumiu um caráter propagandista, já que era premente vender a ideia.

Dessa maneira se configurou a trama de relações propícias ao processo de produção de uma prática discursiva em torno da saúde, instrumentalizada pela Educação e sancionada pelo Estado. Portanto, o encontro - bem sucedido, podemos dizer - entre educação e saúde foi possível pela existência de uma rede de relações:

i. entre o desenvolvimento político-social da Saúde Pública no Brasil e as condições de vida do brasileiro, principalmente os de baixa renda e moradores de áreas periféricas urbanas, nas primeiras duas décadas do século XX;

ii. entre o surgimento e a consolidação científica de disciplinas como a Psicologia, a Sociologia e a Pedagogia e as necessidades de o Estado intervir e controlar a saúde da população;

iii. entre o processo de formação profissional dos dirigentes dos órgãos da Saúde Pública e as inovações do cenário internacional, principalmente nos Estados Unidos;

iv. entre os dispositivos político-legais e os processos de institucionalização da formação profissional em saúde e a configuração dos serviços de saúde pública;

v. entre os interesses político-econômicos da elite política e intelectual brasileira e a conformação do discurso higienista e eugenista;

vi. entre o discurso higienista e a formação da consciência sanitária na população em geral e os recursos, as tecnologias e as instituições educacionais disponíveis no aparelho estatal.

Tal análise fundamenta-se e compartilha da afirmação de Foucault (2010b). Para o autor, um dos grupos de procedimentos que trata de determinar as condições de funcionamento de um dado discurso é a sua forma de apropriação social (Foucault, 2010b). Em uma sociedade 
como a nossa, afirma Foucault (2010b, p. 43-44), a educação é o instrumento pelo qual se pode ter acesso a qualquer tipo de discurso: "todo sistema de educação é uma maneira política de manter ou de modificar a apropriação dos discursos, com os saberes e os poderes que eles trazem consigo".

Nessa conjuntura, a educação sanitária seria "o processo de seleção, organização e aplicação de conhecimentos e métodos das ciências biomédicas e psicossociais visando o desenvolvimento, nos indivíduos e nas sociedades, de sistemas conceituais e de valores que estimulam padrões de vida saudáveis" (Melo, 1976, p. 4).

No entanto, a apropriação social desse discurso não se restringia às crianças. As mães também eram atores sociais desse emaranhado educativo (Figura 3). O principal objetivo era, por meio dessa prática discursiva, desenvolver os hábitos saudáveis. Com isso se desvelava o caráter comportamental e individual da educação sanitária: devia-se ensinar os preceitos da higiene, pois, uma vez aprendidos, modificariam os hábitos das crianças e das mães notadamente, até que fossem capazes de repeti-los de forma automática e com facilidade (Moreno, 1946). Mas como desenvolver esses hábitos saudáveis? Quais instrumentos poderiam ser utilizados? Quem estaria habilitado a executar o processo de sua formação? Para lograr tal objetivo, o ensino formal de tais preceitos foi a grande investida! Essa foi a maneira política de produção de meios para apropriação dos discursos pela massa urbana. Brandão (2007, p. 26) explica que o ensino formal "cria situações próprias para o seu exercício, produz os seus métodos, estabelece suas regras e tempos, e constitui executores especializados”. Evidência de tal afirmação é o guarda-chuva jurídico construído em torno do processo de formação e regulamentação tanto do ensino quanto da prática das educadoras sanitárias no Estado de São Paulo (Candeias, 1988).

Figura 3-Mães Reunidas para Receber Orientações da Educadora Sanitária

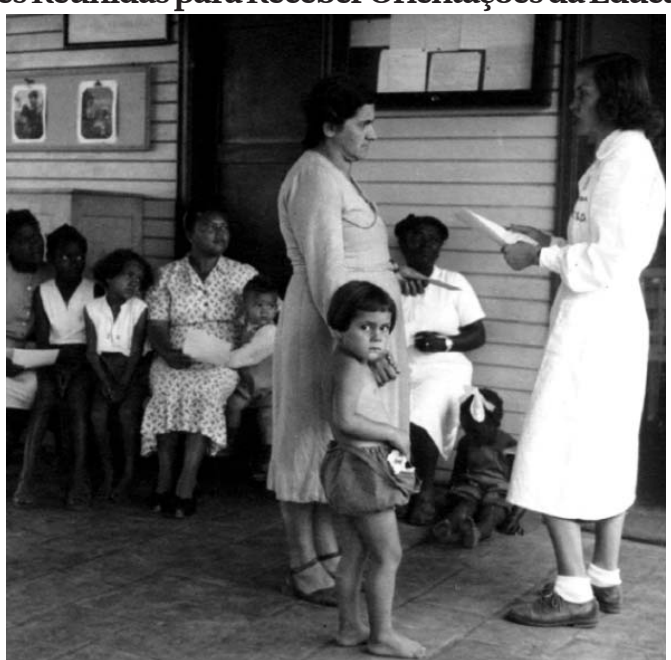

Fonte: Vasconcellos e Rodrigues (2006). 
Nesse contexto, a educação sanitária emerge como a aquisição de hábitos ou a soma de experiências que influenciam favoravelmente os hábitos, um sistema de hábitos integrados na vida cotidiana (Melo, 1976). Investe-se assim naqueles fatores do comportamento e do meio ambiente que podem ser modificados pela educação e que são capazes de contribuir para uma saúde melhor: alimentação, exercício físico, atividade mental, conduta moral e social, controle emocional, asseio, vestuário, prevenção de doenças e acidentes, assistência à saúde, instalações sanitárias convenientes, ventilação, iluminação (Moreno, 1946). Essa abordagem da educação sanitária teve sua hegemonia até a década de 1960, quando ocorreram algumas reformas na estrutura e funcionamento das práticas educativas com enfoque na saúde, conforme veremos a seguir.

\section{Da Educação Sanitária à Educação em Saúde}

As ações de educação sanitária, a partir dos anos 1960, começaram a passar por significativas transformações decorrentes, sobretudo das reformas administrativas ocorridas nos órgãos públicos de gestão da saúde, como o Ministério da Saúde (MS) e de reflexos de eventos internacionais.

Em 1958, a 12a Assembleia Mundial da Saúde, em Genebra, reafirmou o conceito de que a educação sanitária abrange a soma de todas aquelas experiências que modificam ou exercem influência nas atitudes ou condutas de um indivíduo com respeito à saúde. Além disso, salientou os processos necessários para alcançar essas modificações. Já em 1962, na 5a Conferência de Saúde e Educação Sanitária, realizada na Filadélfia, o Diretor Geral da Organização Mundial de Saúde (OMS) assinalou que os serviços de educação sanitária estavam chamados a desempenhar um papel de primeiríssima importância para saltar o abismo que continuava existindo entre descobrimentos científicos da medicina e sua aplicação na vida diária de indivíduos, famílias, escolas e distintos grupos da coletividade (Levy et al., 1997).

Dentre as diversas reorganizações administrativas do MS ocorridas entre 1964 e 1980, podemos destacar: a criação da Superintendência de Campanhas de Saúde Pública (SUCAM); a criação da Fundação Serviço Especial de Saúde Pública (SESP); a implantação dos primeiros sistemas nacionais de informação em saúde (Sistema de Informações sobre Mortalidade - 1976; e o Cadastro de Estabelecimentos de Saúde 1979); e, já no final da década de 1970, a criação da Divisão Nacional de Educação em Saúde da Secretaria Nacional de Ações Básicas de Saúde. Nesse momento se dá a mudança terminológica, como forma de gerar uma transformação conceitual, o que, de fato, não ocorreu (Levy et al., 1997). Além disso, podemos considerar que nas décadas de 1980 e 1990 há dois importantes deslocamentos nos cenários onde se realizavam as práticas de educação em saúde, bem como nos métodos e meios empregados.

$970 \quad$ Educação \& Realidade, Porto Alegre, v. 42, n. 3, p. 961-980, jul./set. 2017. 
Os métodos e meios empregados nas ações de educação sanitária voltadas para o ambiente escolar e o público materno-infantil mostravam-se ineficazes para lograr os objetivos esperados. Ademais, nos anos 1970, as universidades e a política de saúde vinham experimentando formas de ampliação do acesso ao sistema de saúde para a população de áreas urbanas e rurais. Essas iniciativas decorreram do pensamento Preventivista no Brasil (Arouca, 2003) e das discussões nacionais e internacionais impulsionadas pelo movimento da Atenção Primária à Saúde.

Nesse sentido, o centro de saúde que surgiu nos anos 1920 dentro das reformas propostas por Paula Souza numa posição marginal, passa a assumir, gradativamente, um espaço privilegiado na política de saúde brasileira. Tal condição é acentuada com a criação do Sistema Único de Saúde (SUS), em 1988, e ganha força, a partir de 1994, com o Programa de Saúde da Família (PSF, hoje Estratégia de Saúde da Família - ESF) (Mercadante, 2002). Diante disso, configura-se o contexto para realização de alguns deslocamentos.

O primeiro deles diz respeito aos métodos e meios utilizados e ocorre, segundo Levy et al. (1997), em 1989 ao se incorporar ao Projeto Nordeste II o financiamento, pelo Banco Mundial, de US\$ 20 milhões para as ações de Informação, Educação e Comunicação (IEC). Com isso, constituiu-se uma linha de tensão entre aqueles que defendiam os métodos tradicionais de educação em saúde e esse novo movimento (representante do deslocamento em questão) que propugnava a adoção da transmissão do conhecimento através dos modernos meios e técnicas de comunicação de massa.

A utilização dos meios de comunicação de massa nos programas de educação em saúde ganhou reforço a partir de 1996 com o Projeto Saúde na Escola, integrado à TV Escola do Ministério da Educação (MEC), em execução desde 20 de agosto de 1997. Nos anos 1990, esse projeto compôs a grade de programação semanal de 50 mil escolas do ensino fundamental (Levy et al., 1997). Atualmente conta-se também com o Canal Futura, a Telemedicina e a IEC.

O segundo deslocamento corresponde aos cenários de realização das atividades. Se antes tínhamos um direcionamento ao ambiente escolar, atualmente essas ações encontram-se institucionalizadas, de forma mais efetiva, nos centros e postos de saúde dos municípios brasileiros. Com a emergência do Programa de Agentes Comunitários de Saúde (PACS) em 1991 e, posteriormente, com o PSF, esses serviços passaram a compor a rede básica de atenção à saúde, alavancada pela expansão da ESF, principalmente a partir de 1997 (Heimann; Mendonça, 2005). Ou seja, numa análise foucaultiana podemos indicar que as ações de educação em saúde se deslocam, de certa maneira, das instituições ou lócus tradicionais (escola, centros de saúde) e vai para a casa, as ruas, os parques. Um modelo mais difuso, extenso, capilar, fortemente apoiado pela mídia, pelas autoridades conselheiras, pelos modelos de fitness, etc.

Além da constituição da rede básica de serviços de saúde nos municípios, passando a compor um cenário propício à realização das 
atividades de educação em saúde, há de se assinalar a ampliação da abrangência das políticas de saúde brasileiras. Tais políticas, por serem norteadas por princípios do SUS, como universalidade, integralidade, equidade e participação social, têm priorizado a educação para promoção da saúde como eixo transversal às ações propostas de acordo com suas especificidades. Isso tem possibilitado a disseminação da educação em saúde no interior da ESF, lócus privilegiado de efetivação dessas políticas e de coordenação do cuidado dos usuários no sistema de saúde (Brasil, 2012).

O que podemos perceber, chegando neste ponto? Estaríamos hoje diante do mesmo discurso higienista que fomentou a educação sanitária? Ou, contrariamente, podemos afirmar que não se trata do mesmo discurso higienista nem da educação sanitária própria da primeira metade do século XX? Haveria hoje um novo discurso que fundamenta as práticas educativas em saúde?

Para Foucault (2010a), não há, em uma formação discursiva, um encadeamento lógico. O que há é dispersão, coexistência, heterogeneidade, repartição, jogos de inclusão/exclusão, transformação, revezamento, posição, substituição. O que temos é um jogo de relações, como afirma Foucault (2010a), entre os elementos desses discursos. Um jogo descontínuo, sempre liminar, permeado por rupturas entre o novo, o velho e o velho-novo. Discutimos em outros momentos alguns elementos dessas permanências, continuidades, rupturas e, sobretudo, as lutas e resistências existentes aí (Melo, 2013; Melo; Campos, 2014; Melo, 2016). Um jogo em movimento constante, sempre se refazendo, se dispensando, incluindo e excluindo objetos, como discutido a seguir.

\section{Desdobramentos Recentes das Práticas de Educação em Saúde no Brasil}

De acordo com a linha argumentativa construída neste texto, podemos observar que o campo da Educação em Saúde tem incorporado ao seu arsenal teórico e às suas práticas uma série de tecnologias, próprias do desenvolvimento científico-tecnológico dos últimos anos. E, nesse processo, há hibridismo, há sobreposição, há usos de várias tecnologias simultaneamente.

Essas tecnologias abrangem as diversas morfologias da comunicação em massa e, sobretudo, nas redes e mídias sociais e em sites diversos (Moretti; Oliveira; Silva, 2012); as novas tecnologias de cuidado e de gestão do sistema e serviços de saúde; as tecnologias educativas e suas tendências tradicionais e atuais; as tecnologias do eu ou da subjetividade (Rose, 1988); as (bio)tecnologias que atuam, notadamente, na produção de corpos sadios, sarados, belos e que, para isso, exigem disciplina, controle, autoavaliação, automonitoramento, autoinspeção, autoproblematização, confissão (Rose, 1988; Goldenberg; Ramos, 2002; Ortega, 2005).

A articulação desses elementos, suas relações, os interstícios de suas tramas produzem uma mudança de enfoque no campo de ação das 
práticas discursivas da educação em saúde: da organização dos espaços e do tempo, da individualização dos corpos, da constituição de um corpo dócil e útil (educado, portador de bons e saudáveis hábitos de higiene), da ação nas instituições (a escola, a família, o serviço de saúde), da vigilância, da norma e do regulamento, passa-se, gradativamente, a uma ação capilar no cotidiano de vida dos indivíduos, com ênfase no autocuidado, na autorresponsabilização ${ }^{3}$.

O receptor de suas ações e mensagens já não é o indivíduo em particular (a criança, a merendeira, a mãe), mas a massa social abrangida pela mídia e pelos serviços de saúde; a preocupação não se volta ao corpo individual, mas aos processos vitais da população. A população agora abrange a espécie humana em detrimento da anatomopolítica dos corpos. No entanto, é prudente lembrar que via massa se quer o indivíduo! E, com isso, surgem elementos importantes, como os riscos ${ }^{4}$ que precisam conhecer e, no limite, combater.

Nesse contexto, em vez de trabalhar a organização do tempo e do espaço, as ações de educação em saúde buscam abranger os processos de reprodução, a natalidade e mortalidade, as incapacidades biológicas, o meio ambiente. Ou seja, o objeto agora é a vida, principalmente em suas dimensões biológica, social e psicológica. No que tange aos cenários onde tais ações se realizam, há uma tendência de abandonar a exclusividade das instituições, para atingir a comunidade, o bairro, a cidade, os equipamentos sociais, as ruas. No lugar das normas, vigilâncias e regulamentos, vemos emergir os mecanismos reguladores que atuam na subjetividade, no corpo biológico da população. Conforme evidenciado em estudo com grupos de pessoas que vivem com diabetes tipo 2 num centro de saúde da periferia de Campinas, por meio das orientações relativas ao diabetes que se tenta ensinar ao paciente, o saber médico é deslocado das imediações contextuais em que se dá o encontro clínico e passa a desempenhar uma ação capilar no cotidiano de vida dos indivíduos (Melo, 2016).

Trata-se, portanto, da configuração do campo de operação de estratégias biopolíticas engendradas, cotidianamente, pelas práticas de educação em saúde (Gastaldo, 1997; Melo, 2013). Logo, é importante perceber a constituição de um campo de lutas, de resistências e de produção de linhas de fuga no interior das relações sociais que têm como objetivo a execução de ações educativas em saúde.

Os estudos têm mostrado diversos indícios ou evidências desses campos de luta/resistência e linhas de fugas. Da parte dos usuários/cidadãos pode-se observar: a não adesão aos tratamentos e às práticas de cuidados propostas; o silêncio e a indiferença evidenciados, principalmente, pela não participação dos usuários/cidadãos nas ações realizadas e pela não incorporação das informações em seus repertórios de preocupações cotidianas; o uso social das ações educativas muito mais para burlar a burocracia do sistema de saúde, facilitando o acesso a serviços e profissionais, do que pela educação em saúde em si; e a ausência ou baixa frequência nos grupos educativos, nas palestras, nos eventos com propostas educativas (Péres et al., 2007; Barsaglini, 2007; Hull, 2008; Otero; Zanetti; Ogrizio, 2008; Vincent, 2009; Melo; Campos, 2014). 
Viver Através de Projetos de Saúde

No que se refere aos profissionais de saúde, pode-se enumerar: o despreparo pedagógico e a possível falta de interesse em buscar essa preparação, mesmo atuando no contexto do SUS, o que, em tese, possibilita-lhes o acesso à educação permanente e a informações; o não planejamento das ações educativas, o que repercute na baixa qualidade dessas ações e na utilização de referenciais teóricos mais próximos da abordagem tradicional da educação; a reprodução de posturas autoritárias nas suas práticas educativas; os sentimentos de frustração e impotência diante da realidade resistente às mudanças pró-(im)postas; e o desenvolvimento de práticas educativas que produzem um sentimento de culpabilização no usuário/cidadão pelo insucesso do seu tratamento e do seu jeito de andar a vida (L'Abbate, 1994; Torres; Hortale; Schall, 2003; Teixeira; Zanetti, 2006; Péres et al., 2007; Hull, 2008; Oliveira et al, 2009).

Cabe ressaltar que os elementos que operam nesses campos de luta/resistência e as linhas de fuga produzidas são sempre provisórios, processuais, contextuais, historicamente situados, flexíveis. São campos de tensão, de oposição, rupturas, superposições, coexistências, contingências. Talvez uma de suas principais características seja a permeabilidade de suas tensões em variados campos: político, institucional, comunitário, acadêmico-universitário.

Dentre as discussões que vêm sendo realizadas sobre como operar no interior desses campos de tensão, de luta e resistência, os pesquisadores e profissionais de saúde têm dedicado importante espaço nas produções acadêmicas brasileiras, principalmente nas áreas de Enfermagem e de Saúde Coletiva, para o debate das tendências pedagógicas e suas aplicações ao campo da educação em saúde.

Evidencia-se, portanto, a configuração de campos de lutas relacionados às práticas educativas em saúde. Para Foucault (1995), esses campos de lutas consistem em analisar as relações de poder através do antagonismo das estratégias. Com base em Foucault (1995), podemos caracterizar essas lutas contemporâneas, imediatas da seguinte forma:

a. são lutas transversais: não se restringem à educação em saúde, mas permeiam outros espaços de lutas políticas, econômicas e sociais;

b. os objetivos dessas lutas são os efeitos de poder enquanto tal: o que se critica na educação em saúde é o controle que suas práticas e prescrições pretendem exercer sobre os corpos das pessoas, sua saúde, sua vida e, por último, sua morte;

c. são lutas imediatas: criticam as instâncias de poder mais próximas, nesse caso, os profissionais das equipes de saúde e os próprios usuários. Não há um inimigo mor, mas o inimigo imediato, aquele que exerce a ação sobre os indivíduos;

d. são lutas que questionam o estatuto do indivíduo: reivindica-se o direito de ser diferente e resiste-se às prescrições e normatizações que os desconsideram em suas historicidades, desvincula-os de sua vida comunitária. Essas práticas tendem a produzir 
um sentido de individualidade coercitiva, no qual o indivíduo deve se voltar para si mesmo (autorresponsabilização);

e. são opostas aos efeitos de poder relacionados ao saber, à competência e à qualificação: uma luta que se afirma no fosso entre, de um lado, o saber científico e verdadeiro, de outro, o saber popular, leigo, incoerente e promotor de modos de vida não saudáveis;

f. finalmente, todas as lutas contemporâneas giram em torno da questão: quem somos nós? Se tomarmos os objetivos das práticas de educação em saúde, poderíamos nos perguntar também: o que querem fazer de nós? Trata-se, pois, de uma recusa, como afirma o autor, das abstrações produzidas por investigações científicas ou administrativas que tentam determinar quem somos.

Como se pode perceber, são resistências e lutas engendradas nos tensos espaços de produção de cuidados em saúde. Espaços de relações ${ }^{5}$ onde interagem atores sociais diversos: os trabalhadores de saúde, os usuários dos serviços, as instituições públicas e privadas, as organizações comunitárias, a sociedade civil organizada, a indústria de insumos para a saúde, etc. Resistências e lutas que, sem passar pelos crivos das classificações polarizantes (positivas/negativas, boas/más, certas/erradas, produtivas/improdutivas), podem ser consideradas como a força motriz que possibilita a emergência das potências dos encontros.

Para Foucault (1995) - diferente da violência que fecha todas as possibilidades, que atua sobre a passividade do outro e que pretende reduzir as resistências encontradas -, uma relação de poder se articula sobre dois elementos que lhe são indispensáveis: que o outro (aquele sobre o qual ela se exerce) seja inteiramente reconhecido e mantido até o fim como o sujeito de ação; e que se abra, diante da relação de poder, todo um campo de respostas, reações, efeitos, invenções possíveis.

\section{Para não Concluir ou sobre que Vida se Pode Produzir por meio desses Projetos de Saúde?}

Neste ensaio, buscamos analisar a historicidade de algumas práticas de educação em saúde no Brasil tomando como objeto sua emergência histórica nos anos 1920, como educação sanitária, e seus desdobramentos mais recentes. Para alcançar tal objetivo, o referencial teórico empregado possibilitou aos autores produzirem uma operação ensaio, uma vez que se propuseram um pensamento que se experimenta, problematiza e reproblematiza a si mesmo. Nesse sentido, a obra de Michel Foucault, principalmente seus conceitos de práticas discursivas e de biopolítica, permitiram a compreensão das relações de saber-poder que fizeram emergir historicamente a educação em saúde como um campo de saberes e de práticas no interior da saúde pública brasileira. Ademais, salientou-se o caráter biopolítico das ações educativas que tomam a vida e a população como objetos prioritários e sobre eles tentam produzir formas de governo. 
Viver Através de Projetos de Saúde

O estudo permitiu apreender os jogos relacionais entre Educação, Saúde, Estado e Sociedade que reclamaram a constituição da Educação Sanitária como ferramenta higienista e forte aliada do projeto eugenista, que se instalou no Brasil nas primeiras décadas do século XX. Ao mesmo tempo, expôs os agentes (as crianças, as mães, as educadoras sanitárias, os médicos), as instituições (a escola, o centro de saúde, a fábrica) e os discursos (higienista e eugenista) que operavam com o objetivo último de produzir consciência sanitária e, por meio disso, produzir formas de vida saneadas, saudáveis, regradas, dóceis e úteis.

Além disso, foram apresentadas as modificações que tiveram início nos anos 1960 e permitiram deslocamentos tanto nos métodos e meios empregados pela educação em saúde, como nos cenários em que tais práticas se desenvolvem. Com isso, evidenciamos a constituição das justaposiç̃es e dos imbricamentos entre poder disciplinar e biopoder, na medida em que a educação em saúde se capilariza no cotidiano de vida das pessoas, atinge as massas, atualiza seus instrumentos, contemporaniza seus objetos e objetivos. Da vida saneada, regrada, dócil e útil, passamos, de certa forma, à vida saudável. Aqui a própria categoria saudável se renova, amplia seus sentidos e signos, desloca-se do contexto imediato da relação profissional de saúde-usuário para os meios de comunicação de massa, para as redes e mídias sociais, e, assim, chega na casa, no trabalho, na rua, na cama, na escola, no parque. Quiçá viver uma vida saudável hoje equivalha, guardadas as especificidades de cada época, a uma vida normal no século XIX. Se lá era a psiquiatria e o direito penal que produziam os indivíduos perigosos, anormais (Foucault, 2010d), aqui é a clínica, a epidemiologia, o fitness e a nova genética que produzem os projetos de vida que devemos viver - projetos de vidas saudáveis.

Para finalizar, é importante retomar a questão que intitula esta sessão: que vida se pode produzir por meio desses projetos de saúde? Talvez essa resposta possa ser encontrada no cotidiano de vida das pessoas em geral, nas relações sociais engendradas nos serviços de saúde, nas apostas políticas e tecnológicas que visam produzir cuidados singulares, nos campos de lutas que permeiam essas tentativas, na resistência agenciada por sujeitos concretos que se colocam como artesãos de uma existência também concreta e que não cabe nos cálculos e nas projeções da biomedicina.

Recebido em 09 de junho de 2015 Aprovado em 15 de maio de 2017

\section{Notas}

1 Atual Faculdade de Saúde Pública da Universidade de São Paulo.

2 Esses foram, ao menos inicialmente, o grande alvo das ações de educação sanitária. Isto devia-se à influência norte-americana e à possibilidade de investir na educação da criança - principal foco dessas ações em suas fases iniciais. Sobre a escola como centro de disciplinamento dos corpos dóceis por meio de práticas higiênicas moralizadoras e produção de sujeitos eugênicos, ver Marques (1994).

$976 \quad$ Educação \& Realidade, Porto Alegre, v. 42, n. 3, p. 961-980, jul./set. 2017. 
3 Sobre a produção social do indivíduo responsável pela sua saúde, principalmente por meio de ações educativas, ver Lopes (2015).

4 No discurso da saúde pública, o risco sempre se apresentou como aquilo derivado do estilo de vida ou de fatores ambientais que poderiam alterar o estado de saúde da pessoa ou da coletividade. Com os desdobramentos científicos e tecnológicos da "nova genética", o risco genético emerge como uma terceira categoria. O risco genético é um risco corporificado, pois abrange aquilo que o indivíduo carrega em seu corpo - um gene anômalo. Porém, há sobreposições e imbricamentos entre essas categorias de risco, uma vez que os riscos decorrentes do estilo de vida ou do ambiente podem acionar o gene e produzir doenças. Apesar disso, no caso das doenças genéticas, essa genetização social tem redimido o indivíduo de culpas pelo seu comportamento ou adoecimento (Castiel et al., 2006; Conrad; Gabe, 1999).

5 Cumpre lembrar a relevante produção acadêmica de Emerson Elias Merhy a respeito desses espaços de relações. Merhy (2004) discute a existência de uma micropolítica de encontros, sendo estes de dois tipos: encontros de interdição/ dominação e os encontros autopoiéticos (representa o movimento da vida que produz vida). No mesmo estudo o autor discute a noção de relações intercessoras como aquelas produtoras de cuidado em saúde.

\section{Referências}

AGAMBEN, Giorgio. O que é o Contemporâneo? E Outros Ensaios. Chapecó: Argos, 2009.

AROUCA, Sergio. O Dilema Preventivista: contribuição para a compreensão e crítica da Medicina Preventiva. São Paulo: Editora UNESP; Rio de Janeiro: Editora FIOCRUZ, 2003.

BARSAGLINI, Reni Aparecida. "Com Açúcar no Sangue até o Fim": um estudo de caso sobre o viver com diabetes. In: CANESQUI, Ana Maria (Org.). Olhares Socioantropológicos sobre os Adoecidos Crônicos. São Paulo: HUCITEC; FAPESP, 2007. P. 53-85.

BRANDÃO, Carlos Rodrigues. O que é Educação? Coleção Primeiros Passos. São Paulo: Brasiliense, 2007.

BRASIL. Ministério da Saúde. Secretaria de Atenção à Saúde. Departamento de Atenção Básica. Política Nacional de Atenção Básica. Série E. Brasília: Ministério da Saúde, 2012.

CANDEIAS, Nelly Martins Ferreira. Evolução Histórica da Educação em Saúde como Disciplina de Ensino na Faculdade de Saúde Pública da Universidade de São Paulo - 1925 a 1967. Revista de Saúde Pública, São Paulo, v. 22, n. 4, p. 34765, ago. 1988.

CASTIEL, Luis David et al. Os Riscos Genômicos e a Responsabilidade Pessoal em Saúde. Revista Panamericana de Salud Pública, Washington, v. 19, n. 3, p. 189-97, mar. 2006.

CONRAD, Peter; GABE, Jonathan (Org.). Sociological Perspectives on the New Genetics. Oxford: Blackwell Publishers, 1999.

CORTEZ, Adamastor. Centro de Saúde de São Paulo. 1926. Tese (Doutorado em Medicina) - Faculdade de Medicina de São Paulo, São Paulo, 1926.

DE QUEIRÓZ PÉREZ-RAMOS, Aidyl. Resgatando a Memória dos Patronos - Geraldo Horácio Paula Souza - Cadeira no 30. Boletim Academia Paulista de Psicologia, São Paulo, v. 26, n. 1, p. 18-28, jan./abr. 2006. 
FOUCAULT, Michel. O Sujeito e o Poder. In: DREYFUS, Hubert; RABINOW, Paul (Org.). Michel Foucault, uma Trajetória Filosófica: para além do estruturalismo e da hermenêutica. Rio de Janeiro: Forense Universitária, 1995. P. 231-49.

FOUCAULT, Michel. Em Defesa da Sociedade: curso no Collège de France, ano 1975-1976. Coleção Tópicos. São Paulo: Martins Fontes, 2002.

FOUCAULT, Michel. A Arqueologia do Saber. 7 ed. Rio de Janeiro: Forense Universitária, 2010a.

FOUCAULT, Michel. A Ordem do Discurso: aula inaugural no Collège de France, pronunciada em 2 de novembro de 1970. 20 ed. São Paulo: Edições Loyola, 2010b. FOUCAULT, Michel. História da Sexualidade I: a vontade de saber. 20ª reimpressão. Rio de Janeiro: Graal, 2010c.

FOUCAULT, Michel. Os Anormais: curso no Collège de France (1974-1975). 2. ed. Coleção Obras de Michel Foucault. São Paulo: Editora WMF Martins Fontes, 2010d.

GASTALDO, Denise Maria. É a Educação em Saúde "Saudável”? Repensando a Educação em Saúde através do Conceito de Bio-Poder. Educação \& Realidade, Porto Alegre, v. 22, n. 1, p. 147-68, jan./jun. 1997.

GIL, Antônio Carlos. Métodos e Técnicas em Pesquisa Social. 5 ed. São Paulo: Atlas, 1999.

GOLDENBERG, Mirian; RAMOS, Marcelo Silva. A Civilização das Formas: o corpo como valor. In: GOLDENBERG, Mirian (Org.). Nu e Vestido. Rio de Janeiro: Record, 2002. P. 19-40.

HEIMANN, Luiza Sterman; MENDONÇA, Maria Helena Magalhães de. A Trajetória da Atenção Básica em Saúde e do Programa de Saúde da Família no SUS: uma busca de identidade. In: LIMA, Nísia Trindade et al. (Org.). Saúde e Democracia: história e perspectivas do SUS. Rio de Janeiro: Editora Fiocruz, 2005. P. 481-502.

HULL, Linda. Diabetes Mellitus: a case history of community care. Journal of Community Nursing, Surrey, v. 22, n. 4, p. 4-11, 2008.

L'ABBATE, Solange. Educação em Saúde: uma nova abordagem. Cadernos de Saúde Pública, Rio de Janeiro, v. 10, n. 4, p. 481-490, out./dez. 1994.

LARROSA, Jorge. A Operação Ensaio: sobre ensaiar e o ensaiar-se no pensamento, na escrita e na vida. Educação \& Realidade, Porto Alegre, v. 29, n. 1, p. 27-43, jan./jun. 2004.

LEVY, Sylvain Nahum et al. Educação em Saúde: histórico, conceitos e propostas. Brasília: Ministério da Saúde, 1997.

LOPES, Andréia Aparecida Ferreira. Cuidado e Empoderamento: a construção do sujeito responsável por sua saúde na experiência do diabetes. Saúde e Sociedade, São Paulo, v. 24, n. 2, p. 486-500, jun. 2015.

MARQUES, Vera Regina Beltrão. A Medicalização da Raça: médicos, educadores e discurso eugênico. Campinas: Editora da UNICAMP, 1994.

MELO, Joaquim Alberto Cardoso. A Prática de Saúde e a Educação. 1976. 155 f. Tese (Doutorado em Saúde Pública) - Faculdade de Ciências Médicas, Universidade Estadual de Campinas, Campinas, 1976.

MELO, Lucas Pereira de. Análise Biopolítica do Discurso Oficial sobre Educação em Saúde para Pacientes Diabéticos no Brasil. Saúde e Sociedade, São Paulo, v. 22, n. 4, p. 1216-1225, out./dez. 2013.

978 Educação \& Realidade, Porto Alegre, v. 42, n. 3, p. 961-980, jul./set. 2017 
MELO, Lucas Pereira de. É como uma Família: significados atribuídos a grupos de educação em saúde sobre diabetes por profissionais da saúde. Ciência e Saúde Coletiva, Rio de Janeiro, v. 21, n. 8, p. 2497-2505, ago. 2016.

MELO, Lucas Pereira de; CAMPOS, Edemilson Antunes de. "O Grupo Facilita Tudo": significados atribuídos por pacientes portadores de diabetes mellitus tipo 2 a grupos de educação em saúde. Revista Latino-Americana de Enfermagem, Ribeirão Preto, v. 22, n. 6, p. 980-7, nov./dez. 2014.

MERCADANTE, Otávio Azevedo et al. Evolução das políticas e do sistema de saúde no Brasil. In: FINKELMAN, Jacobo (Org.). Caminhos da Saúde Pública no Brasil. Rio de Janeiro: Editora Fiocruz, 2002. P. 236-95.

MORENO, Nicolino. Saúde e Educação. Arquivo de Higiene e Saúde Pública, v. 11, n. 29, p. 425-35, 1946.

MORETTI, Felipe Azevedo; OLIVEIRA, Vanessa Elias de; SILVA, Edina Mariko Koga da. Acesso a Informações de Saúde na Internet: uma questão de saúde pública? Revista da Associação Médica Brasileira, São Paulo, v. 58, n. 6, p. 6508, dez. 2012.

OLIVEIRA, Nunila Ferreira et al. Fatores Terapêuticos em Grupo de Diabéticos. Revista da Escola de Enfermagem da USP, São Paulo, v. 43, n. 3, p. 558-65, set. 2009.

ORTEGA, Francisco. Da Ascese à Bio-Ascese ou do Corpo Submetido à Submissão ao Corpo. In: RAGO, Margareth; ORLANDI, Luiz Lacerda; VEIGA-NETO, Alfredo (Org.). Imagens de Foucault e Deleuze: ressonâncias nietzschianas. Rio de Janeiro: DP \& A, 2005. P. 139-73.

OTERO, Ludmila Miyar; ZANETTI, Maria Lúcia; OGRIZIO, Michelle Daguano. Conhecimento do Paciente Diabético acerca de sua Doença, Antes e Depois da Implantação de um Programa de Educação em Diabetes. Revista Latino-americana de Enfermagem, Ribeirão Preto, v. 16, n. 2, p. 231-237, mar./abr. 2008.

PÉRES, Denise Siqueira et al. Dificuldades dos Pacientes Diabéticos para o Controle da Doença: sentimentos e comportamentos. Revista Latino-americana de Enfermagem, Ribeirão Preto, v. 15, n. 6, p. 1105-1112, nov./dez. 2007.

PRIOR, Lindsay. Using Documents in Social Research. London: Sage, 2011.

ROSE, Nicholas. Governando a Alma: a formação do eu privado. In: SILVA, Tomaz Tadeu (Org.). Liberdades Reguladas. Petrópolis-RJ: Vozes, 1988. P. 30-45.

SÃO PAULO. Decreto no 3.876, de 11 de julho de 1925. Reorganisa o Serviço Sanitario e repartições dependentes. Diário Official [do Estado de São Paulo], São Paulo, SP, n. 161, 26 jul. 1925. P. 5235-5264.

SÃO PAULO. Lei no 2.121, de 30 de dezembro de 1925. Approva o decreto n. 3 876, de 11 de Julho de 1925, que reorganisou o Serviço Sanitario e repartições dependentes. Diário Official [do Estado de São Paulo], São Paulo, SP, n. 3, 05 jan. 1926. P. 124-128.

SÃO PAULO. Decreto-Lei no 13.040, em 31 de dezembro de 1942. Dispõe sobre criação da Escola de Enfermagem. Diário Oficial [do Estado de São Paulo], São Paulo, SP, n. 246, 01 nov. 1942. P. 01.

TEIXEIRA, Carla Regina de Souza; ZANETTI, Maria Lúcia. O Trabalho Multiprofissional com Grupo de Diabéticos. Revista Brasileira de Enfermagem, Brasília, v. 59, n. 6, p. 812-817, nov./dez. 2006.

TORRES, Heloisa de Carvalho; HORTALE, Virginia Alonso; SCHALL, Virginia. A Experiência de Jogos em Grupos Operativos na Educação em Saúde para Diabéticos. Cadernos de Saúde Pública, Rio de Janeiro, v. 19, n. 4, p. 1039-47, jul./ ago. 2003.

Educação \& Realidade, Porto Alegre, v. 42, n. 3, p. 961-980, jul./set. 2017. 
VASCONCELLOS, Maria da Penha; RODRIGUES, Jaime. A fotografia como Instrumento do Trabalho do Higienista (São Paulo, primeira metade do século XX). História, Ciências, Saúde - Manguinhos, Rio de Janeiro, v. 13, n. 2, p. 477-91, abr./jun. 2006.

VINCENT, Deborah. Culturally Tailored Education to Promote Lifestyle Change in Mexican Americans with Type 2 Diabetes. Journal of the American Academy of Nurse Practitioners, Austin, v. 21, n. 9, p. 520-7, 2009.

Lucas Pereira de Melo é doutor em Ciências pela Universidade de São Paulo (USP) e mestre em Enfermagem pela Universidade Estadual de Campinas (UNICAMP). Professor Adjunto do Curso de Medicina Multicampi, Escola Multicampi de Ciências Médicas da Universidade Federal do Rio Grande do Norte (UFRN).

E-mail: lucasenf@yahoo.com.br

Ana Luiza de Oliveira e Oliveira é mestre e doutora em Saúde Coletiva pela Universidade Estadual de Campinas (UNICAMP). Fisioterapeuta pela Pontifícia Universidade Católica de Campinas (PUC-Campinas). Professora Adjunta do Curso de Medicina Multicampi, Escola Multicampi de Ciências Médicas da Universidade Federal do Rio Grande do Norte (UFRN). Especialista em Saúde Coletiva pelo Instituto de Saúde de São Paulo.

E-mail: aluloli@gmail.com 